\title{
LEPROSY IN THE ERA OF IMMUNOSUPPRESSION: DO WE NEED TO WORRY? EPIDEMIOLOGICAL DATA IN BRAZIL FROM 2015-2017
}

Gustavo Tedde Filho (Faculdade de Medicina- Centro Universitário de Brasília, Brasilia, DF, Brasil), Mariana Silva Nunes (Faculdade de Medicina- Centro Universitário de Brasília, Brasilia, DF, Brasil), João Carlos Geber Júnior (Hospital Anchieta, Brasilia, DF, Brasil), Viviane Cristina Uliana Peterle ( Faculdade de Medicina- Escola Superior de Ciências da Saúde, Brasilia, DF, Brasil), Ana Paula Monteiro Gomides (Faculdade de Medicina- Centro Universitário de Brasília, Brasilia, DF, Brasil)

\section{BACKGROUND}

Leprosy is a chronic infectious disease caused by Mycobacterium leprae, its main sites being the skin and peripheral nerves. Brazil is the second country in number of cases, losing only to India. Due to the high number of cases and the possibility of musculoskeletal manifestations of the disease, rheumatologists should be aware of the possibility of this diagnosis both as primary disease and in patients immunosuppressed by other rheumatic diseases or use of medications.

The objective of this study was to evaluate the number of new cases in Brazil from 2015 to 2017.

\section{MATERIALS AND METHODS}

Descriptive, ecological study, in a time series, based on data obtained from the SINAN and the General Coordination of Leprosy and Diseases in Elimination (CGHDE). Data were collected on patients with leprosy in the period 2015 to 2017. Variables analyzed: new cases per state, cutaneous lesions, clinical forms and therapeutic schemes.

\section{RESULTS}

In the period 2015-2017, 76.919 new cases of leprosy were reported in Brazil, with the highest number of cases occurring in the Northeast region (TABLE 1). There was a prevalence of 2-5 cutaneous lesions (TABLE 2 ), and the clinical form with the largest number of cases was dimorphic (TABLE 3 ). As for the therapeutic scheme, the most used was the MDT / MB / 12 doses (TABLE 4).

TABLE 1: New cases of leprosy by region of Brazil in the period 2015-2017

Region New cases 2015-2017

TOTAL 76.919

North $\quad 14.817$

Northeast $\quad 33.750$

South 2.555

Southeast $\quad 10.322$

Midwest $\quad 14.942$

TABLE 2: Skin lesions of leprosy in the period 2015-2017.

SKIN LESION NUMBER OF CASES 


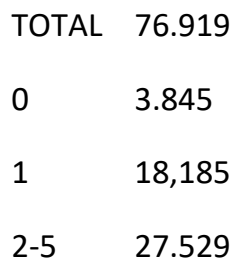

TABLE 3: Clinical forms of leprosy in the period 2015-2017

CLINICAL FORMS NUMBER OF CASES

TOTAL 76.919

Ignored 2.932

Undetermined $\quad 10.707$

Tuberculoid $\quad 11.715$

Dimorph $\quad 34.899$

Virchowiana $\quad 12.307$

Unclassified $\quad 4.359$

TABLE 4: Therapeutic schemes of leprosy in the period 2015-2017

THERAPEUTIC SCHEMES NUMBER OF CASES

TOTAL 76.919

Ignored 135

PQT 6 doses $\quad 21.877$

PQT 12 doses $\quad 54.424$

Other alternative schemes

483

\section{CONCLUSION}

Brazil is an endemic country in leprosy and has presented a considerable number of new cases in three years. It is up to the rheumatologist to have a high level of suspicion for proper management and prevention of sequelae. 